\title{
Reaction intermediates during operando electrocatalysis identified from full solvent quantum mechanics molecular dynamics
}

\author{
Tao Cheng ${ }^{\mathrm{a}, \mathrm{b}, \mathrm{c}}$, Alessandro Fortunellic, ${ }^{\mathrm{c},}$, and William A. Goddard III,c,1 \\ anstitute of Functional Nano \& Soft Materials (FUNSOM), Jiangsu Key Laboratory for Carbon-Based Functional Materials \& Devices, Joint International \\ Research Laboratory of Carbon-Based Functional Materials and Devices, Soochow University, Suzhou, 215123, Jiangsu, PR China; bJoint Center for Artificial

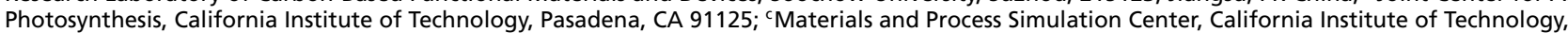 \\ Pasadena, CA 91125; and ' Italian National Council for Research-Institute for the Chemistry of OrganoMetallic Compounds, Consiglio Nazionale delle \\ Ricerche, Pisa 56124, Italy
}

Contributed by William A. Goddard III, January 28, 2019 (sent for review December 20, 2018; reviewed by Sharon Hammes-Schiffer, Philippe Sautet, and Richard J. Saykally)

\begin{abstract}
Electrocatalysis provides a powerful means to selectively transform molecules, but a serious impediment in making rapid progress is the lack of a molecular-based understanding of the reactive mechanisms or intermediates at the electrode-electrolyte interface (EEI). Recent experimental techniques have been developed for operando identification of reaction intermediates using surface infrared (IR) and Raman spectroscopy. However, large noises in the experimental spectrum pose great challenges in resolving the atomistic structures of reactive intermediates. To provide an interpretation of these experimental studies and target for additional studies, we report the results from quantum mechanics molecular dynamics (QM-MD) with explicit consideration of solvent, electrode-electrolyte interface, and applied potential at $298 \mathrm{~K}$, which conceptually resemble the operando experimental condition, leading to a prototype of operando QM-MD (o-QM-MD). With o-QM-MD, we characterize 22 possible reactive intermediates in carbon dioxide reduction reactions $\left(\mathrm{CO}_{2} \mathrm{RRs}\right)$. Furthermore, we report the vibrational density of states ( $v$-DoSs) of these intermediates from two-phase thermodynamic (2PT) analysis. Accordingly, we identify important intermediates such as chemisorbed $\mathrm{CO}_{2}\left(b-\mathrm{CO}_{2}\right),{ }^{*} \mathrm{HOC}-\mathrm{COH},{ }^{*} \mathrm{C}-\mathrm{CH}$, and ${ }^{*} \mathrm{C}-\mathrm{COH}$ in our o-QM-MD likely to explain the experimental spectrum. Indeed, we assign the experimental peak at 1,191 cm-1 to the mode of C-O stretch in * $\mathrm{HOC}-\mathrm{COH}$ predicted at $1,189 \mathrm{~cm}^{-1}$ and the experimental peak at $1,584 \mathrm{~cm}^{-1}$ to the mode of $\mathrm{C}-\mathrm{C}$ stretch in ${ }^{*} \mathrm{C}-\mathrm{COD}$ predicted at $1,581 \mathrm{~cm}^{-1}$. Interestingly, we find that surface ketene $\left({ }^{*} \mathrm{C}=\mathrm{C}=0\right)$, arising from ${ }^{*} \mathrm{HOC}-\mathrm{COH}$ dehydration, also shows signals at around $1,584 \mathrm{~cm}^{-1}$, which indicates a nonelectrochemical pathway of hydrocarbon formation at low overpotential and high $\mathrm{pH}$ conditions.
\end{abstract}

quantum mechanics | molecular dynamics | vibration mode

$\mathrm{CO}_{2}$ reduction reaction | reaction mechanism

$\mathbf{E}^{1}$ ectrocatalytic reactions play a key role in many modern and emerging critical technologies such as energy conversion and storage, sensors, organic synthesis, and biomolecular electronics. However, with very few exceptions, a fundamental understanding of electrocatalytic reactions remains poor and nonpredictive. This is because electrocatalytic reactions are extremely complex. The factors determining reaction pathways depend on the relative rates of the several competing intermediate steps. Moreover, these reactions take place in a strong electric field of the electric double layer (EDL). Along with the structure of the catalyst surface, the structure of the EDL controls the thermodynamics and kinetics of the elementary steps through the polarization and local microenvironment of the adsorbed species, interfacial charge transfer, and mass transfer to/from the catalytic site. These critical phenomena must be understood at the atomistic level to use them in developing new strategies for improving the efficiency of electrocatalytic processes. This makes atomistic molecular-level understanding of electrocatalytic reactions is a scientific grand challenge.
Current understanding of electrode-electrolyte interfaces (EEIs) generally rests on continuum concepts of the EDL developed by Gouy, Chapman, Stern, and others. These theoretical models address the structural and electrical organization of the EDL, but have not been connected to the detailed atomistic description of reactions and electron/proton transfer at the molecular level of quantum mechanics (QM), nor have they been adequately validated experimentally due to the limitations of available techniques.

To provide an atomistic-level understanding of the nature of the EEI during electrocatalytic reactions (or operando), we have been using metadynamics reactive dynamics with QM-based forces to determine the free-energy barriers and onset potentials at $298 \mathrm{~K}$, which we have applied to the carbon dioxide $\left(\mathrm{CO}_{2}\right)$ reduction reaction $\left(\mathrm{CO}_{2} \mathrm{RR}\right)$. We use these results to elucidate the details of atom/charge flow and chemical transformations, electron/proton transfer, and ion transfer, and how they depend on applied potential $(U)$. We expect that this will dramatically accelerate the development of electrocatalysis-based technologies.

$\mathrm{CO}_{2} \mathrm{RR}$ has been studied extensively because of its central role in closing the carbon loop $(1,2)$. Electrocatalytically

\section{Significance}

The gap preventing a direct comparison between experiment and atomic simulation still exists due to the unrealistic consideration of the operando experimental condition in commonly used quantum mechanics (QM). In this work, we advanced the QM-based simulation of the electrode-electrolyte interface with explicit consideration of solvent and applied voltage to produce reactive trajectories as input for a two-phase thermodynamics model in generating vibrational density of states that can be directly compared with the reported experimental spectroscopy. After resolving the signals, we successfully distinguished the reactive intermediates in a carbon dioxide reduction reaction, which provides an atomic-scale understanding of this important reaction.

Author contributions: T.C. and W.A.G. designed research; T.C. and A.F. performed research; T.C. and W.A.G. analyzed data; and T.C., A.F., and W.A.G. wrote the paper.

Reviewers: S.H.-S., Yale University; P.S., University of California, Los Angeles; and R.J.S., University of California, Berkeley.

The authors declare no conflict of interest.

Published under the PNAS license.

See Commentary on page 7611.

${ }^{1}$ To whom correspondence should be addressed. Email: wag@caltech.edu.

This article contains supporting information online at www.pnas.org/lookup/suppl/doi:10 . 1073/pnas.1821709116/-/DCSupplemental.

Published online March 13, 2019. 
reducing $\mathrm{CO}_{2}$ efficiently provides a means for both reducing the amount of $\mathrm{CO}_{2}$ in the atmosphere from human activities and converting renewable energy (such as solar, wind, hydropower, etc.) into chemical forms, which facilitates the energy storage (3-7). $\mathrm{CO}_{2} \mathrm{RR}$ to hydrocarbons is one of these promising solutions, which has been significantly advanced in the last $30 \mathrm{y}$ (8-11) since the pioneering work of Hori et al. in 1985 (12). Copper $(\mathrm{Cu})$ is the only single-metal electrocatalyst that produces significant amounts of hydrocarbons (3) and thus has been investigated extensively as a prototype for understanding the reaction mechanism both in experiment and in theory $(8,9,13-22)$. Carbon monoxide $(\mathrm{CO})$ is the first stable product from $\mathrm{CO}_{2} \mathrm{RR}$ which can be further reduced to hydrocarbons (such as methane, ethylene, ethanol, etc.) at sufficiently negative potentials. Subtle changes (such as $\mathrm{Cu}$ facet, $\mathrm{pH}$, the presence of oxygen, etc.) are observed to have a significant impact on the activity and selectivity for $\mathrm{CO}_{2} \mathrm{RR}$ or CORR. Very recently, we found that water also participates in CORR via nonelectrochemical reactions, which further complicates the reaction network (23). To understand and explain these intriguing experimental observations, we need to predict and validate the fundamental reaction mechanism at the atomic scale.

Atomic-scale computational simulations have been applied extensively to investigate various aspects of $\mathrm{CO}_{2} \mathrm{RR}$ and CORR on $\mathrm{Cu}(15,16,22)$, but many simulations did not include a realistic description of the solvent and applied potentials. Recently, we reported the reaction mechanism and kinetics with full explicit solvent and grand canonical QM simulations of the EEI to mimic operando experimental conditions (24). Using this unified framework, we systematically investigated the reaction mechanism of $\mathrm{CO}_{2} \mathrm{RR}$ and CORR on $\mathrm{Cu}$ (100) to 12 kinds of hydrocarbons (25-27). To confirm the presence of these predicted reaction intermediates in operando experiments, we report here their fundamental vibrational density of states ( $v$-DoSs) using operando quantum mechanics molecular dynamics (o-QM-MD) to closely simulate the operando experimental conditions, including the isotope shifts for ${ }^{12} \mathrm{C}$ to ${ }^{13} \mathrm{C}$, ${ }^{16} \mathrm{O}$ to ${ }^{18} \mathrm{O}$, and $\mathrm{H}$ to $\mathrm{D}$, which sets the stage for experimental validation for the details of these $o$-QM-MD simulations. We are most interested in the longlifetime reactive intermediates that may be observed experimentally, which provides a means of using the experiment to extract critical information about the reaction mechanism. With the key intermediates identified, experiments can then obtain detailed kinetic parameters providing a means for optimizing the kinetic processes.

The Performance of Perdew, Burke, and Ernzerhof Functional To benchmark the performance of $\mathrm{QM}$ at the level of Perdew, Burke, and Ernzerhof (PBE) density functional theory (DFT), we calculated the vibrational frequencies of 14 isolated molecules $\left(\mathrm{CH}_{4}, \mathrm{C}_{2} \mathrm{H}_{2}, \mathrm{C}_{2} \mathrm{H}_{4}, \mathrm{C}_{2} \mathrm{H}_{6}, \mathrm{CH}_{2} \mathrm{OH}-\mathrm{CH}_{2} \mathrm{OH}\right.$, $\mathrm{CH}_{3} \mathrm{CH}_{2} \mathrm{OH}, \mathrm{CH}_{3} \mathrm{CHO}, \mathrm{CH}_{3} \mathrm{COOH}, \mathrm{CH}_{3} \mathrm{OH}, \mathrm{CHO}-\mathrm{CH}_{2} \mathrm{OH}$, $\mathrm{CHO}-\mathrm{CHO}, \mathrm{H}_{2} \mathrm{O}, \mathrm{HCOOH}$, and $\mathrm{CH}_{2}=\mathrm{CHOH}$ ), the experimental data of which are available to compare with. As shown in $S I$ Appendix, Fig. S1, $v$-QM predictions well reproduce the experimental frequencies with linear correlation of 1.0015 (shown in $S I$ Appendix, Fig. S1). Thus, scaling factors are not necessary.

\section{$v$-DoS from o-QM-MD}

Vacuum QM ( $v$-QM) has been extensively used in predicting the vibrational frequencies of intermediates at interface. However, we suspect that $v$-QM is not suitable for the EEI because the dynamics of the $\mathrm{H}_{2} \mathrm{O}$ interacting with the reaction intermediates strongly affect the vibrational modes. In this work, we carried out explicit solvent calculation to simulate a water/Cu (100) interface and finely tuned the work function to match the experimentally applied voltage, as we did in our previous work (24). We further extended the $o$-QM-MD to $20 \mathrm{ps}$ to produce a sufficiently long trajectory as input of the two-phase thermodynamic (2PT) model (28) to generate the $v$-DoSs, which can be directly compared with operando experimental measurements. The details of the 2PT procedure for extracting the vibrational frequencies from $o$-QM-MD at $298 \mathrm{~K}$ are in SI Appendix. Using this framework, we systematically predicted the $v$-DoS of 22 intermediates from $o$-QM-MD (SI Appendix, Fig. S5). To compare, we also calculated the vibrational frequencies of these 22 intermediates from $v$-QM, in which the electrode was included and optimized, but without solvent or applied potential.

\section{$\mathrm{CO}_{2} \mathrm{RR}$ to $\mathrm{CO}$}

In our previous work, we predicted that the $\mathrm{CO}_{2} \mathrm{RR}$ to $\mathrm{CO}$ involves physisorbed $\mathrm{CO}_{2}\left(l-\mathrm{CO}_{2}\right)$, chemisorbed $\mathrm{CO}_{2}\left({ }^{*} \mathrm{CO}_{2}^{\sigma e-}\right.$ or $\left.b-\mathrm{CO}_{2}\right),{ }^{*} \mathrm{COOH}$, and $\mathrm{CO}$ at $\mathrm{pH} 7$ as follows (25):

$$
l-\mathrm{CO}_{2} \stackrel{0.43 e V}{\rightarrow} b-\mathrm{CO}_{2} \stackrel{0.37 e V}{\rightarrow} * \mathrm{COOH}^{0.30 e V} * \mathrm{CO} .
$$

The predicted $v$-DoSs from the 2PT analysis are shown in Fig. 1. The detailed results are as follows:

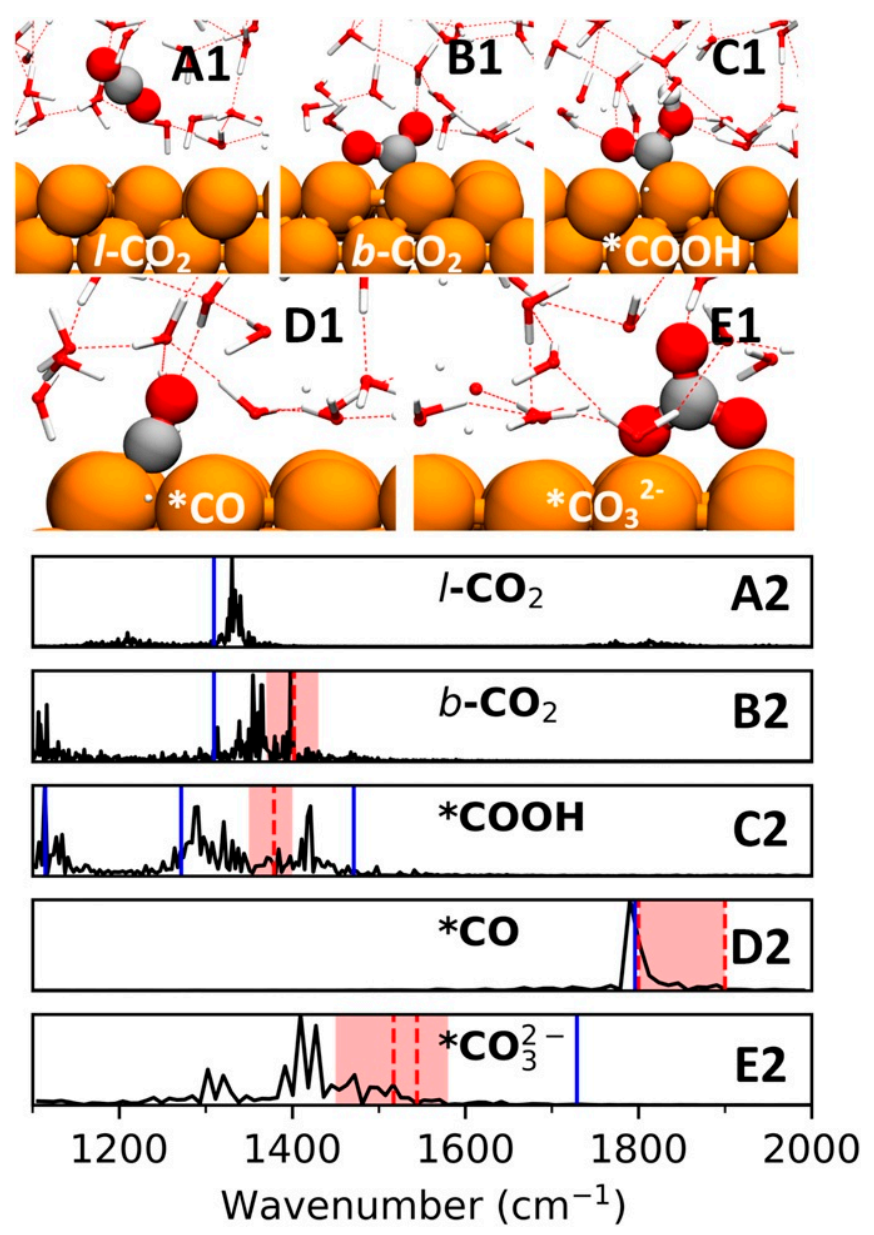

Fig. 1. Snapshots $(A 1-E 1)$ of the structures and $v$-DoSs $(A 2-E 2)$ of physisorbed $\mathrm{CO}_{2}\left(I-\mathrm{CO}_{2}\right)$, chemisorbed $\mathrm{CO}_{2}\left(b-\mathrm{CO}_{2}\right),{ }^{*} \mathrm{COOH}$, ${ }^{*} \mathrm{CO}$, and ${ }^{*} \mathrm{CO}_{3}^{2-}$ from o-QM-MD simulations and 2PT analysis. In A1-E1, the color codes are $\mathrm{Cu}$ in orange, $\mathrm{O}$ in red, $\mathrm{C}$ in silver, and $\mathrm{H}$ in white. The hydrogen bonds are shown as dashed red lines. In A2-E2, $v$-Dos from o-QM-MD is shown as a solid black line, the experimental frequencies are shown as a red dashed line, and the vibrational frequencies from $v$-QM optimization are shown as solid blue lines for comparison. $\left(I-\mathrm{CO}_{2}\right.$ and $b-\mathrm{CO}_{2}$ are the same from $v$-QM, because $b-\mathrm{CO}_{2}$ is unstable in vacuum and automatically converts to $I-\mathrm{CO}_{2}$ after optimization.) 

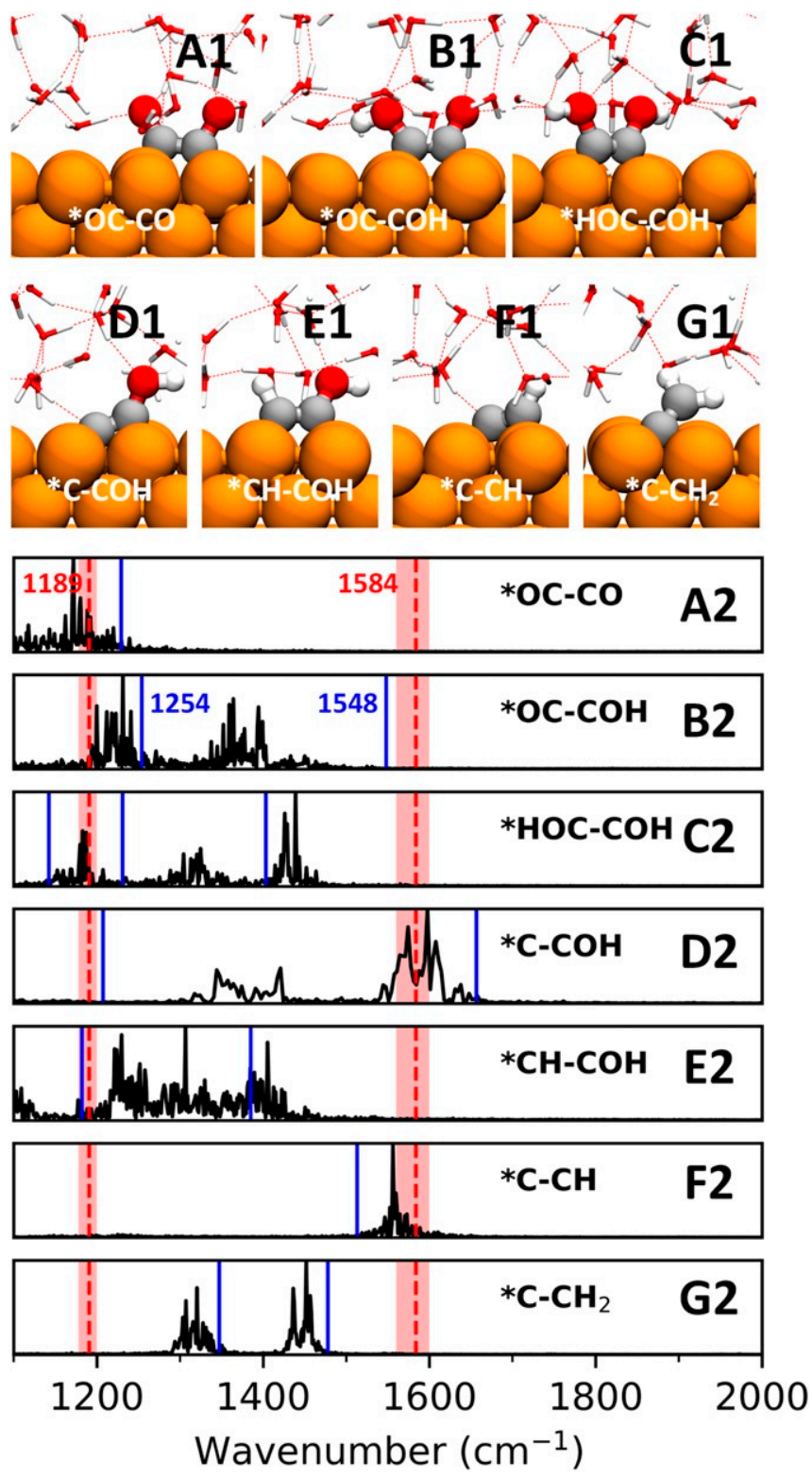

Fig. 2. Snapshots $(A 1-G 1)$ and $v$-DoSs $(A 2-G 2)$ for ${ }^{*} \mathrm{OC}-\mathrm{CO}$, ${ }^{*} \mathrm{OC}-\mathrm{COH}$ ${ }^{*} \mathrm{HOC}-\mathrm{COH},{ }^{*} \mathrm{C}-\mathrm{COH},{ }^{*} \mathrm{CH}-\mathrm{COH},{ }^{*} \mathrm{C}-\mathrm{CH},{ }^{*} \mathrm{C}-\mathrm{CH}_{2}$, and ${ }^{*} \mathrm{C}=\mathrm{C}=\mathrm{O}$. Notations are the same as in Fig. 1.

- For $l-\mathrm{CO}_{2}$, the peak at $1,330 \mathrm{~cm}^{-1}$ is the $\mathrm{O}=\mathrm{C}=\mathrm{O}$ symmetrical stretch, which is IR inactive but Raman active.

- For $b-\mathrm{CO}_{2}$, the peaks at $1,365 \mathrm{~cm}^{-1}$ and $1,397 \mathrm{~cm}^{-1}$ are the two $\mathrm{C}=\mathrm{O}$ stretch modes from one $\mathrm{C}=\mathrm{O}$ parallel and the other about $60^{\circ}$ with the surface. The $v$-QM of $l-\mathrm{CO}_{2}$ and $b$ $\mathrm{CO}_{2}$ are the same because $b-\mathrm{CO}_{2}$ is unstable in vacuum and automatically converts to $l-\mathrm{CO}_{2}$ after optimization.

- For ${ }^{*} \mathrm{COOH}$, the peak at $1,420 \mathrm{~cm}^{-1}$ is the $\mathrm{C}=\mathrm{O}$ stretch, while $1,287 \mathrm{~cm}^{-1}$ is C-OH in-plane bend. Note that the $v$-QM calculation gives symmetric and antisymmetric $\mathrm{CO}$ stretch at $1,248 \mathrm{~cm}^{-1}$ and $1,481 \mathrm{~cm}^{-1}$ but the hydrogen bonds (HBs) with $\mathrm{H}_{2} \mathrm{O}$ lead to about $50 \mathrm{~cm}^{-1}$ redshifts of these two peaks.

- For * $\mathrm{CO}, 1,790 \mathrm{~cm}^{-1}$ is $\mathrm{C}=\mathrm{O}$ stretch of $\mathrm{CO}$ adsorbed on bridge sites. Instead, $\mathrm{CO}$ adsorbed on top sites leads to IR modes from $2,050 \mathrm{~cm}^{-1}$ to $2,100 \mathrm{~cm}^{-1}$ (29). The $\mathrm{CO}$ adsorbed on bridge sites has been observed but is considered inert to chemical reactions, thus having a longer lifetime (30).
- We assigned the surface-bounded ${ }^{*} \mathrm{CO}_{3}$ as carbonic acid based on the geometric features for $v$-QM optimization. As shown in SI Appendix, Table S1, one C-O bond is significantly shorter $(1.214 \AA)$ than the other two bonds $(1.366 \AA)$, as expected for one $\mathrm{C}=\mathrm{O}$ double bond and two $\mathrm{C}-\mathrm{O}$ single bonds, which is also consistent with the frequency analysis shown in Fig. $1 E 2$ and SI Appendix, Fig. S5: $1,720 \mathrm{~cm}^{-1}$ corresponds to $\mathrm{C}=\mathrm{O}$ double-bond stretch and $986 \mathrm{~cm}^{-1}$ corresponds to $\mathrm{C}$ $\mathrm{O}$ single-bond stretch. When this ${ }^{*} \mathrm{CO}_{3}$ is solvated in water with one $\mathrm{Na}^{+}$cation in $o-\mathrm{QM}-\mathrm{MD}$, the Bader charge analysis predicts a net charge of $-1.08 e^{-}$, close to -1 . However, after analyzing the bond distance of $o$-QM-MD, we found that the bond distances of $\mathrm{C}-\mathrm{O}$ are $1.289 \AA, 1.311 \AA$, and $1.312 \AA$, significantly different from carbonic acid, but close to ${ }^{*} \mathrm{CO}_{3}^{2-}$ anions (shown in SI Appendix, Table S1). Because the Bader charge analysis is usually less reliable than the geometry analysis, at this negative applied potential we consider ${ }^{*} \mathrm{CO}_{3}$ as ${ }^{*} \mathrm{CO}_{3}^{2-}$ anions, although the carbonic form $\mathrm{O}=\mathrm{CO}_{2}^{-}$may exist at positive potentials. This requires further study.

The spectroscopy of $\mathrm{CO}_{2} \mathrm{RR}$ to $\mathrm{CO}$ has been extensively reported experimentally (20,29-35). However, the assignments of the observed peaks remain controversial. We find that $b-\mathrm{CO}_{2}$, ${ }^{*} \mathrm{COOH}$, and ${ }^{*} \mathrm{CO}_{3}^{2-}$ all exhibit comparable spectroscopy signals at $1,400 \mathrm{~cm}^{-1}$, making it difficult to distinguish them. According to the reaction mechanism (Eq. 1), at $\mathrm{pH} 7$ the population of $b-\mathrm{CO}_{2}$ is likely higher than that of ${ }^{*} \mathrm{COOH}$. Thus, we consider that the peaks observed at $1,400 \mathrm{~cm}^{-1}$ come from mostly $b-\mathrm{CO}_{2}$ although ${ }^{*} \mathrm{CO}_{3}^{2-}$ is long lived and has signals at $1,400 \mathrm{~cm}^{-1}$. Because ${ }^{*} \mathrm{CO}_{3}^{2-}$ also has unique peaks at $1,034 \mathrm{~cm}^{-1}$ and $1,516 \mathrm{~cm}^{-1}$ (SI Appendix, Fig. S5), these peaks together could help to identify ${ }^{*} \mathrm{CO}_{3}^{2-}$ (35).

\section{CORR to $\mathrm{C}_{2} \mathrm{H}_{4}$ and $\mathrm{C}_{2} \mathrm{H}_{5} \mathrm{OH}$}

The CORR has been studied more thoroughly because both the overall potential-determining step and the rate-determining step lie within the CORR. $\mathrm{Cu}(100)$ is capable of reducing $\mathrm{CO}$ to ethylene $\left(\mathrm{C}_{2} \mathrm{H}_{2}\right)$ at high $\mathrm{pH}$. In our previous work, we predicted that the QM-based reaction mechanism at $\mathrm{pH} 7$ and $\mathrm{pH} 12$ involves at least eight intermediates as follows: (26)

$$
\begin{gathered}
{ }^{*} \mathrm{CO}+{ }^{*} \mathrm{CO} \stackrel{0.69 e V}{\rightarrow} * \mathrm{OC}-\mathrm{CO} \stackrel{0.24 e V}{\rightarrow} * \mathrm{OC}-\mathrm{COH} \\
\stackrel{0.08 e V}{\rightarrow} * \mathrm{HOC}-\mathrm{COH} \stackrel{0.63 e V}{\rightarrow} * \mathrm{C}-\mathrm{COH} \stackrel{0.44 e V}{\rightarrow} * \mathrm{CH}-\mathrm{COH} \\
\stackrel{0.61 e V}{\rightarrow} * \mathrm{C}-\mathrm{CH} \stackrel{0.60 e V}{\rightarrow}{ }^{\mathrm{C}-\mathrm{CH}_{2}} \\
\stackrel{0.49 e V}{\rightarrow}{ }^{\mathrm{CH}-\mathrm{CH}_{2}} \stackrel{0.38 e V}{\rightarrow} * \mathrm{C}_{2} \mathrm{H}_{4} .
\end{gathered}
$$

The simulated $v$-DoSs are shown in Fig. 2.

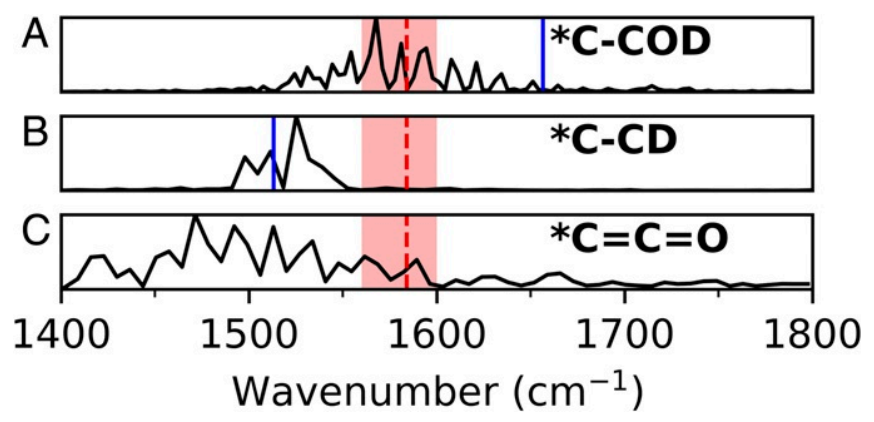

Fig. 3. $v$-DoS of ${ }^{2} \mathrm{H}(\mathrm{D})$-labeled $(A){ }^{*} \mathrm{C}-\mathrm{COD},(B){ }^{*} \mathrm{C}-\mathrm{CD}$, and $(C){ }^{*} \mathrm{C}=\mathrm{C}=\mathrm{O}$ in $\mathrm{D}_{2} \mathrm{O}$ solvent. The frequencies of ${ }^{*} \mathrm{C}=\mathrm{C}=\mathrm{O}$ from $\mathrm{v}-\mathrm{QM}$ are $2,078 \mathrm{~cm}^{-1}$ and $1,211 \mathrm{~cm}^{-1}$ out of the range shown here $\left(1,400-1,800^{-1}\right)$. 


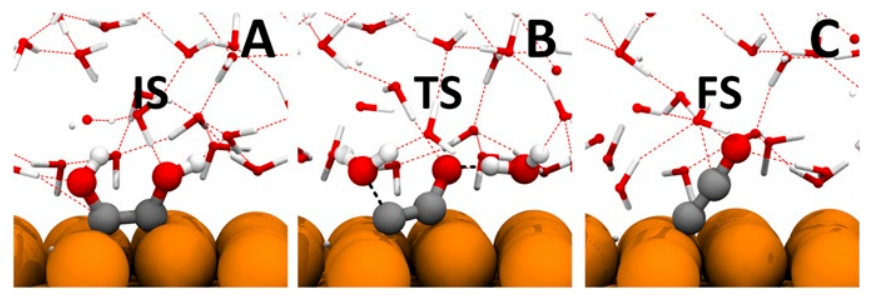

Fig. 4. $(A-C)$ The snapshots of the initial state (IS, *HOC-COH) $(A)$, the transition state $\left(\mathrm{TS},{ }^{*} \mathrm{H}_{2} \mathrm{O}-\mathrm{C}-\mathrm{CO}-\mathrm{H}_{2} \mathrm{O}\right)(B)$, and the final state $\left(\mathrm{FS},{ }^{*} \mathrm{C}=\mathrm{C}=\mathrm{O}\right)(C)$ of reaction 3 .

- For *OC-CO, $1,171 \mathrm{~cm}^{-1}$ is from C-O ${ }^{-}$stretch. Here, $v$-QM gives symmetric and antisymmetric stretch at $1,039 \mathrm{~cm}^{-1}$ and $1,229 \mathrm{~cm}^{-1}$ but they are decoupled to $1,171 \mathrm{~cm}^{-1}$ in $o-\mathrm{QM}$ MD. Because the barrier is only $0.24 \mathrm{eV}$ to the next species, this mode is unlikely to be observed.

- For *OC-COH, 1,231 $\mathrm{cm}^{-1}$ is H-O-C in-plane bend, and the peaks around $1,360 \mathrm{~cm}^{-1}$ are from $\mathrm{C}=\mathrm{O}$ stretch. Because the barrier is only $0.08 \mathrm{eV}$ to the next species, this mode is unlikely to be observed.

- For ${ }^{*} \mathrm{HOC}-\mathrm{COH}, 1,439 \mathrm{~cm}^{-1}$ is from $\mathrm{C}=\mathrm{C}$ stretch, $1,324 \mathrm{~cm}^{-1}$ is from $\mathrm{H}-\mathrm{O}-\mathrm{C}=\mathrm{C}-\mathrm{O}-\mathrm{H}$ symmetric in-plane bend, and $1,187 \mathrm{~cm}^{-1}$ is from C-OH stretch. Since the barrier is $0.63 \mathrm{eV}$ to the next step, these modes are likely to be observed.

- For ${ }^{*} \mathrm{C}-\mathrm{COH}, 1,609 \mathrm{~cm}^{-1}$ is from $\mathrm{C}=\mathrm{C}$ stretch, which has the character of a $\mathrm{C}-\mathrm{C}$ triple bond. because the barrier is $0.44 \mathrm{eV}$ to the next step, these modes might be observed.

- For ${ }^{*} \mathrm{CH}-\mathrm{COH}, 1,422 \mathrm{~cm}^{-1}$ is from $\mathrm{C}=\mathrm{C}$ stretch, and $1,251 \mathrm{~cm}^{-1}$ is from $\mathrm{C}-\mathrm{OH}$ stretch. Because the barrier is $0.61 \mathrm{eV}$ to the next step, these modes are likely to be observed.

- For ${ }^{*} \mathrm{C}-\mathrm{CH}, 1,559 \mathrm{~cm}^{-1}$ is from $\mathrm{C}=\mathrm{C}$ stretch. Because the barrier is $0.60 \mathrm{eV}$ to the next step, these modes are likely to be observed.

- For ${ }^{*} \mathrm{C}-\mathrm{CH}_{2}$, both $1,451 \mathrm{~cm}^{-1}$ and $1,320 \mathrm{~cm}^{-1}$ are from $\mathrm{C}=\mathrm{C}$ stretch. Because the barrier is $0.49 \mathrm{eV}$ to the next step, these modes might not be observed.

At low potential in LiOH solutions, Pérez-Gallent et al. (20) experimentally distinguished two unique peaks, $1,191 \mathrm{~cm}^{-1}$ and $1,584 \mathrm{~cm}^{-1}$, and assigned $1,191 \mathrm{~cm}^{-1}$ as C-OH stretch of ${ }^{*} \mathrm{OC}-$ $\mathrm{COH}$. We find three early intermediates $\left({ }^{*} \mathrm{OC}-\mathrm{CO},{ }^{*} \mathrm{OC}-\mathrm{COH}\right.$, and $\left.{ }^{*} \mathrm{HOC}-\mathrm{COH}\right)$ with modes in this region but only ${ }^{*} \mathrm{HOC}-$ $\mathrm{COH}$ is predicted to be a long-lived species. Thus, we assign its mode at $1,189 \mathrm{~cm}^{-1}$ of ${ }^{*} \mathrm{HOC}-\mathrm{COH}$ to the $1,191 \mathrm{~cm}^{-1}$ from the experiment.

The other peak at $1,584 \mathrm{~cm}^{-1}$ is more intriguing. PérezGallent et al. (20) assigned this peak as the $\mathrm{C}=\mathrm{O}$ stretch of ${ }^{*} \mathrm{OC}-\mathrm{COH}$ based on a $v$-QM calculation that predicted a peak at $1,576 \mathrm{~cm}^{-1}$. Indeed, in our $v$-QM calculation we find this mode at $1,548 \mathrm{~cm}^{-1}$ (Fig. 2B2) too. However, with solvation and applied potential, this $1,548 \mathrm{~cm}^{-1}$ peak significantly redshifts to $1,360 \mathrm{~cm}^{-1}$, which is unlikely to explain the experiment. Instead, we find that ${ }^{*} \mathrm{C}-\mathrm{COH}$ with a peak at $1,609 \mathrm{~cm}^{-1}$ and ${ }^{*} \mathrm{C}-\mathrm{CH}$ with a peak at $1,559 \mathrm{~cm}^{-1}$ are more likely to explain the experimental peak at $1,584 \mathrm{~cm}^{-1}$. Both of these peaks correspond to a C-C triple bond interacting with the surface. Because the barrier out of ${ }^{*} \mathrm{C}-\mathrm{CH}$ is $0.60 \mathrm{eV}$ while that out of ${ }^{*} \mathrm{C}-\mathrm{COH}$ is $0.44 \mathrm{eV}$, it may be that the observed line is dominated by the ${ }^{*} \mathrm{C}-\mathrm{CH}$, but we expect that the ${ }^{*} \mathrm{C}-\mathrm{COH}$ with a larger dipole might have a stronger intensity.

\section{Isotope Simulations}

The mode at $1,584 \mathrm{~cm}^{-1}$ can only be observed using $\mathrm{D}_{2} \mathrm{O}$ solvent; otherwise, it is fully covered by a water $\mathrm{O}-\mathrm{H}$ bending band (from $1,650 \mathrm{~cm}^{-1}$ to $1,450 \mathrm{~cm}^{-1}$ ). To directly compare with experiment, we carried out isotope simulations replacing all $\mathrm{H}$ with $\mathrm{D}$ and calculated the $v$-DoSs of two possible candidates $\left({ }^{*} \mathrm{C}\right.$ $\mathrm{COD}$ and ${ }^{*} \mathrm{C}-\mathrm{CD}$ ) as shown in Fig. 3 . Both ${ }^{*} \mathrm{C}-\mathrm{COD}$ and ${ }^{*} \mathrm{C}-\mathrm{CD}$ exhibit about $25 \mathrm{~cm}^{-1}$ redshift due to the isotope effect, which leaves *C-COD as a better candidate to explain the experiment.

To provide the basis for definitive experimental validation we also report the isotope effects of ${ }^{13} \mathrm{C}$ and ${ }^{18} \mathrm{O}$ for these modes in SI Appendix, Fig. S6, which could serve a guidance for future isotope experiments.

\section{Surface Ketene}

Interestingly, we find that ${ }^{*} \mathrm{C}=\mathrm{C}=\mathrm{O}$ also exhibits signals in the $1,584-\mathrm{cm}^{-1}$ region as shown in Fig. $3 C$. This is surprising because $v$-QM predicts only two peaks at $1,211 \mathrm{~cm}^{-1}$ and $2,078 \mathrm{~cm}^{-1}$, which are from $\mathrm{O}=\mathrm{C}=\mathrm{C}$ asymmetric and symmetric stretch, but the peaks at the $1,584-\mathrm{cm}^{-1}$ range are absent. We attribute the emergence of $1,584 \mathrm{~cm}^{-1}$ of ${ }^{*} \mathrm{C}=\mathrm{C}=\mathrm{O}$ at the CORR condition for two reasons: First, ${ }^{*} \mathrm{C}=\mathrm{C}=\mathrm{O}$ is likely negative charged; and second, ${ }^{*} \mathrm{C}=\mathrm{C}=\mathrm{O}$ always interacts with water via $\mathrm{HB}$, which weakens the $\mathrm{C}=\mathrm{O}$ double band, leaving $\mathrm{C}=\mathrm{C}$ sharing the triplebond character similarly to ${ }^{*} \mathrm{C}-\mathrm{COH}$, which is another case that shows the critical role of $o-\mathrm{QM}-\mathrm{MD}$ in predicting the operando experiment.

The presence of surface ketene $\left({ }^{*} \mathrm{C}=\mathrm{C}=\mathrm{O}\right)$ was first proposed by Calle-Vallejo and Koper (15). In our previous work, we found that ${ }^{*} \mathrm{C}=\mathrm{C}=\mathrm{O}$ is thermodynamically stable, but kinetically inhibited due to the high free-energy barrier $(0.69 \mathrm{eV})$. Therefore, we previously excluded ${ }^{*} \mathrm{C}=\mathrm{C}=\mathrm{O}$ as a major intermediate. In this work, we found an additional pathway of ${ }^{*} \mathrm{C}=\mathrm{C}=\mathrm{O}$ formation from ${ }^{*} \mathrm{HOC}-\mathrm{COH}$ via dehydration as follows:

$$
{ }^{*} \mathrm{HOC}-\mathrm{COH} \stackrel{\mathrm{H}_{2} \mathrm{O}}{\rightarrow} \mathrm{C}=\mathrm{C}=\mathrm{O}+\mathrm{H}_{2} \mathrm{O} .
$$

The snapshots of the initial state, the transition state, and the final state are shown in Fig. 4. $o-\mathrm{QM}-\mathrm{MD}$ free-energy calculations predicted the barrier to be $0.59 \mathrm{eV}$, which is similar to the other barriers involved in CORR. Thus, it is very possible that ${ }^{*} \mathrm{C}=\mathrm{C}=\mathrm{O}$ could present as a long-lived intermediate especially at low overpotential and high $\mathrm{pH}$, in which condition nonelectrochemical reactions are promoted because the electrochemical reactions are suppressed.

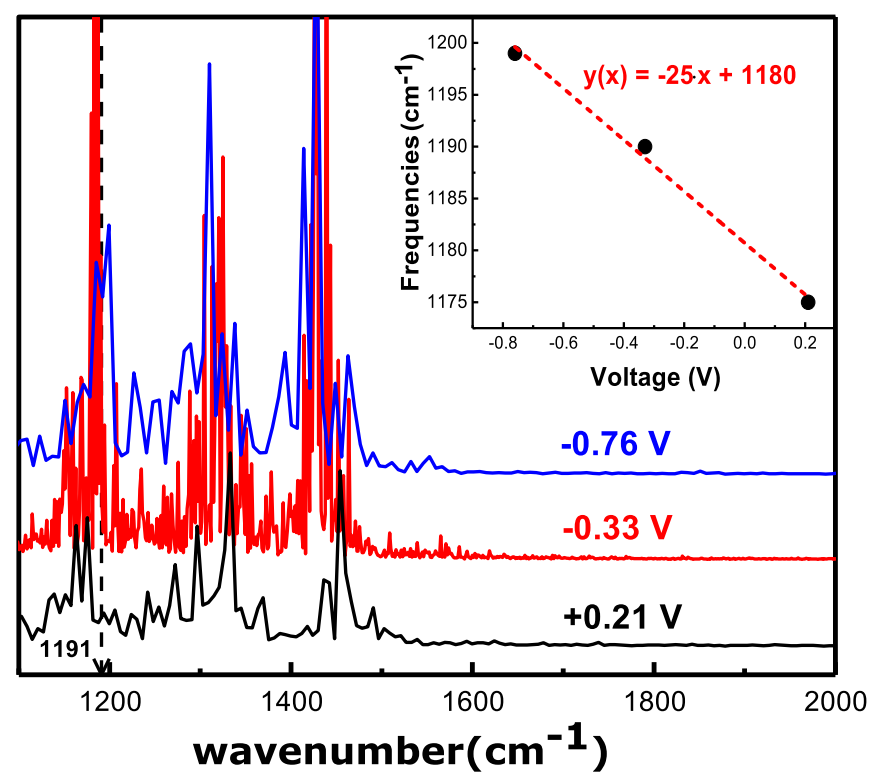

Fig. 5. The simulated potential-dependent $v$-DoSs of $* \mathrm{HOC}-\mathrm{COH}$ at +0.21 $\mathrm{V},-0.33 \mathrm{~V}$, and $-0.76 \mathrm{~V}$. Inset shows the blue shift of the $1,191-\mathrm{cm}^{-1}$ peak (a feature of $\mathrm{C}-\mathrm{O}$ stretch of $\mathrm{C}-\mathrm{OH}$ ) as a function of applied potential. 


\section{Stark Effect}

Taking * HOC-COH as an example, we carried out simulations at $+0.21 \mathrm{~V},-0.33 \mathrm{~V}$, and $-0.76 \mathrm{~V}$ to investigate the electric field effect by removing one electron ( +1 net charge), staying neutral, and adding one electron ( -1 net charge). The predicted $v$-DoS is shown in Fig. 5. As discussed above, we have distinguished the $1,191 \mathrm{~cm}^{-1}$ wavenumber as a feature of ${ }^{*} \mathrm{HCO}-\mathrm{COH}$. We found this $1,191 \mathrm{~cm}^{-1}$ wavenumber undergoes a blue shift as applied potentials become more negative with a rate of about $25 \mathrm{~cm}^{-1} /$ $\mathrm{V}$, which reasonably agrees with experimental observations (20).

\section{Summary}

We carried out 20-ps o-QM-MD simulations to determine the vibrational frequencies at $298 \mathrm{~K}$ to identify possible reactive intermediates in $\mathrm{CO}_{2} \mathrm{RR}$ to $\mathrm{CO}$ and $\mathrm{CORR}$ to $\mathrm{C}_{2} \mathrm{H}_{4}$ while including an explicit solvent and the effect of the applied potential. We find significant differences in the vibrational frequency predictions between traditional $v$-QM and $o-\mathrm{QM}-\mathrm{MD}$ for cases such as ${ }^{*} \mathrm{CO}_{3},{ }^{*} \mathrm{OC}-\mathrm{COH}$, and ${ }^{*} \mathrm{C}=\mathrm{C}=\mathrm{O}$. Thus, we recommend $o$-QM-MD as a more reliable method to simulate and interpret the experimental spectroscopy at operando conditions.

From $o$-QM-MD 2PT analysis, we assign the following: the experimental peak at $1,191 \mathrm{~cm}^{-1}$ to $\mathrm{C}-\mathrm{O}$ stretch of ${ }^{*} \mathrm{HOC}$ $\mathrm{COH}$, which is predicted at $1,189 \mathrm{~cm}^{-1}$ from $o-\mathrm{QM}-\mathrm{MD}$, and the

1. Aresta M, Dibenedetto A, Angelini A (2014) Catalysis for the valorization of exhaust carbon: From $\mathrm{CO}_{2}$ to chemicals, materials, and fuels. Technological use of $\mathrm{CO}_{2}$. Chem Rev 114:1709-1742.

2. Otto A, Grube T, Schiebahn S, Stolten D (2015) Closing the loop: Captured $\mathrm{CO}_{2}$ as a feedstock in the chemical industry. Energy Environ Sci 8:3283-3297.

3. Hori Y (2008) Electrochemical $\mathrm{CO}_{2}$ reduction on metal electrodes. Modern Aspects of Electrochemistry, eds Vayenas C, White R, Gamboa-Aldeco M (Springer, New York), Vol 42, pp 89-189.

4. Kortlever R, Shen J, Schouten KJP, Calle-Vallejo F, Koper MTM (2015) Catalysts and reaction pathways for the electrochemical reduction of carbon dioxide. J Phys Chem Lett 6:4073-4082.

5. Gattrell M, Gupta N, Co A (2006) A review of the aqueous electrochemical reduction of $\mathrm{CO}_{2}$ to hydrocarbons at copper. J Electroanal Chem 594:1-19.

6. Kondratenko EV, Mul G, Baltrusaitis J, Larrazabal GO, Perez-Ramirez J (2013) Status and perspectives of $\mathrm{CO}_{2}$ conversion into fuels and chemicals by catalytic, photocatalytic and electrocatalytic processes. Energy Environ Sci 6:3112-3135.

7. Schouten KJP, Calle-Vallejo F, Koper MTM (2014) A step closer to the electrochemical production of liquid fuels. Angew Chem Int Ed 53:10858-10860.

8. Liu M, et al. (2016) Enhanced electrocatalytic $\mathrm{CO}_{2}$ reduction via field-induced reagent concentration. Nature 537:382-386.

9. Li CW, Ciston J, Kanan MW (2014) Electroreduction of carbon monoxide to liquid fuel on oxide-derived nanocrystalline copper. Nature 508:504-507.

10. Dinh $\mathrm{CT}$, et al. (2018) $\mathrm{CO}_{2}$ electroreduction to ethylene via hydroxide-mediated copper catalysis at an abrupt interface. Science 360:783-787.

11. Mariano RG, McKelvey K, White HS, Kanan MW (2017) Selective increase in $\mathrm{CO}_{2}$ electroreduction activity at grain-boundary surface terminations. Science 358: 1187-1192.

12. Hori Y, Kikuchi K, Suzuki S (1985) Production of $\mathrm{CO}$ and $\mathrm{CH}_{4}$ in electrochemical reduction of $\mathrm{CO}_{2}$ at metal electrodes in aqueous hydrogen carbonate solution. Chem Lett 14:1695-1698.

13. Kuhl KP, Cave ER, Abram DN, Jaramillo TF (2012) New insights into the electrochemical reduction of carbon dioxide on metallic copper surfaces. Energy Environ Sci 5:7050-7059.

14. Schouten KJP, Qin Z, Gallent EP, Koper MTM (2012) Two pathways for the formation of ethylene in CO reduction on single-crystal copper electrodes. J Am Chem Soc 134:9864-9867.

15. Calle-Vallejo F, Koper MTM (2013) Theoretical considerations on the electroreduction of $\mathrm{CO}$ to $\mathrm{C} 2$ species on $\mathrm{Cu}(100)$ electrodes. Angew Chem 52:7282-7285.

16. Nie X, Esopi MR, Janik MJ, Asthagiri A (2013) Selectivity of $\mathrm{CO}_{2}$ reduction on copper electrodes: The role of the kinetics of elementary steps. Angew Chem 52:2459-2462.

17. Schouten KJP, Pérez Gallent E, Koper MTM (2014) The influence of pH on the reduction of $\mathrm{CO}$ and to hydrocarbons on copper electrodes. J Electroanal Chem 716:53-57.

18. Montoya JH, Shi C, Chan K, Nørskov JK (2015) Theoretical insights into a CO dimerization mechanism in $\mathrm{CO}_{2}$ electroreduction. J Phys Chem Lett 6:2032-2037. experimental peak at $1,584 \mathrm{~cm}^{-1}$ to $\mathrm{C}-\mathrm{C}$ stretch of ${ }^{*} \mathrm{C}-\mathrm{COD}$, which is predicted at $1,581 \mathrm{~cm}^{-1}$ from $o$-QM-MD.

Furthermore, we identified ${ }^{*} \mathrm{C}=\mathrm{C}=\mathrm{O}$, coming from an additional pathway of ${ }^{*} \mathrm{HOC}-\mathrm{COH}$ dehydration, as another possible long-lived intermediate via a nonelectrochemical reaction, which likely explains the hydrocarbon formation [such as acetate $\left(\mathrm{CH}_{3} \mathrm{COO}^{-}\right)$and ethanol] at low overpotentials using oxygenderived $\mathrm{Cu}$ nanoparticles (NPs) or $\mathrm{Cu}$ NPs with rich grain boundaries (9).

This combination of $o-\mathrm{QM}-\mathrm{MD}$ and experiment uses the best aspects of each: $o$-QM-MD can predict the atomic structures but is limited in timescale, size scale, and accuracy. Instead, experiments can characterize the real system and provide signals produced by some intermediate, but have difficulties in resolving the atomic structure of reactive intermediates. Combining them fills the gap to provide the means of fully understanding the EEI and using this to design dramatically improved electrocatalytic processes.

ACKNOWLEDGMENTS. This work was supported by the Joint Center for Artificial Photosynthesis, a Department of Energy (DOE) Energy Innovation Hub, supported through the Office of Science of the US DOE under Award DESC0004993. These studies used the Extreme Science and Engineering Discovery Environment which is supported by National Science Foundation Grant ACl-1053575. This work is supported by Collaborative Innovation Center of Suzhou Nano Science \& Technology, the Priority Academic Program Development of Jiangsu Higher Education Institutions (PAPD), the 111 Project.

19. Verdaguer-Casadevall A, et al. (2015) Probing the active surface sites for CO reduction on oxide-derived copper electrocatalysts. J Am Chem Soc 137:9808-9811.

20. Pérez-Gallent E, Figueiredo MC, Calle-Vallejo F, Koper MTM (2017) Spectroscopic observation of a hydrogenated $\mathrm{CO}$ dimer intermediate during $\mathrm{CO}$ reduction on $\mathrm{Cu}(100)$ electrodes. Angew Chem 56:3621-3624.

21. Garza AJ, Bell AT, Head-Gordon M (2018) Mechanism of $\mathrm{CO}_{2}$ reduction at copper surfaces: Pathways to C2 products. ACS Catal 8:1490-1499.

22. Peterson AA, Abild-Pedersen F, Studt F, Rossmeisl J, Norskov JK (2010) How copper catalyzes the electroreduction of carbon dioxide into hydrocarbon fuels. Energy Environ Sci 3:1311-1315.

23. Lum Y, Cheng T, Goddard WA, Ager JW (2018) Electrochemical CO reduction builds solvent water into oxygenate products. J Am Chem Soc 140:9337-9340.

24. Cheng T, Wang L, Merinov BV, Goddard WA (2018) Explanation of dramatic pHdependence of hydrogen binding on noble metal electrode: Greatly weakened water adsorption at high pH. J Am Chem Soc 140:7787-7790.

25. Cheng T, Xiao H, Goddard WA (2016) Reaction mechanisms for the electrochemical reduction of $\mathrm{CO}_{2}$ to $\mathrm{CO}$ and formate on the $\mathrm{Cu}(100)$ surface at $298 \mathrm{~K}$ from quantum mechanics free energy calculations with explicit water. J Am Chem Soc 138:1380213805.

26. Cheng $\mathrm{T}$, Xiao $\mathrm{H}$, Goddard WA (2017) Full atomistic reaction mechanism with kinetics for $\mathrm{CO}$ reduction on $\mathrm{Cu}(100)$ from ab initio molecular dynamics free-energy calculations at 298 K. Proc Natl Acad Sci USA 114:1795-1800.

27. Cheng $\mathrm{T}$, Xiao $\mathrm{H}$, Goddard WA (2017) Nature of the active sites for $\mathrm{CO}$ reduction on copper nanoparticles; suggestions for optimizing performance. J Am Chem Soc 139:11642-11645.

28. Lin ST, Maiti PK, Goddard WA (2010) Two-phase thermodynamic model for efficient and accurate absolute entropy of water from molecular dynamics simulations. $J$ Phys Chem B 114:8191-8198.

29. Heyes J, Dunwell M, Xu B (2016) $\mathrm{Co}_{2}$ reduction on $\mathrm{Cu}$ at low overpotentials with surface-enhanced in situ spectroscopy. J Phys Chem C 120:17334-17341.

30. Gunathunge CM, Ovalle VJ, Li Y, Janik MJ, Waegele MM (2018) Existence of an electrochemically inert $\mathrm{CO}$ population on Cu electrodes in alkaline $\mathrm{pH}$. ACS Catal 8:7507-7516.

31. Figueiredo MC, Ledezma-Yanez I, Koper MTM (2016) In situ spectroscopic study of $\mathrm{CO}_{2}$ electroreduction at copper electrodes in acetonitrile. ACS Catal 6:2382-2392.

32. Pérez-Gallent E, Marcandalli G, Figueiredo MC, Calle-Vallejo F, Koper MTM (2017) Structure- and potential-dependent cation effects on $\mathrm{CO}$ reduction at copper singlecrystal electrodes. J Am Chem Soc 139:16412-16419.

33. Zhu S, Jiang B, Cai WB, Shao M (2017) Direct observation on reaction intermediates and the role of bicarbonate anions in $\mathrm{CO}_{2}$ electrochemical reduction reaction on $\mathrm{Cu}$ surfaces. J Am Chem Soc 139:15664-15667.

34. Gunathunge $C M$, et al. (2017) Spectroscopic observation of reversible surface reconstruction of copper electrodes under $\mathrm{CO}_{2}$ reduction. J Phys Chem C 121:12337-12344.

35. Chernyshova IV, Somasundaran P, Ponnurangam S (2018) On the origin of the elusive first intermediate of $\mathrm{CO}_{2}$ electroreduction. Proc Natl Acad Sci USA 115:E9261-E9270. 